\title{
Partial synchronization of spermatogenesis in the immature Djungarian hamster, but not in the immature Wistar rat
}

\author{
L. H. Van Haaster and D. G. De Rooij* \\ Department of Cell Biology, Utrecht University, Medical School, Utrecht, The Netherlands
}

\begin{abstract}
The frequencies of the cellular associations of the seminiferous epithelium were determined at various ages after birth in immature Djungarian hamsters and Wistar rats. The frequencies of the cellular associations present in immature animals were then compared with the frequencies of the corresponding pooled stages in adult animals. At 15 days of age, the cellular associations present in Djungarian hamsters could be divided into four groups based on the presence of $A_{3}$, intermediate (In), or $B\left(B_{1}\right.$ and $B_{2}$ ) spermatogonia, or preleptoteneleptotene-zygotene spermatocytes. Compared with adult animals, the group containing spermatocytes was found to be enriched by $52 \%$, while the frequency of the B spermatogonia was reduced by $55 \%$. At 22 days of age, the cellular associations of spermatogenesis were classified into five groups: pachytene spermatocytes associated with $\mathrm{A}_{3}$ spermatogonia, In spermatogonia, $\mathrm{B}$ spermatogonia, or preleptotene-leptotenezygotene spermatocytes, or the meiotic divisions. The stages containing preleptoteneleptotene-zygotene spermatocytes and those containing $A_{3}$ spermatogonia were enriched by $35 \%$ and $59 \%$ compared with adult values, respectively. The meiotic divisions were enriched by $21 \%$, but this increase was not significant. The frequency of the B spermatogonia was reduced by $62 \%$. In addition, the synchronization factor, calculated with the computer program SYNTEST, was increased to $1.48 \pm 0.05$ (mean \pm SEM) and $1.38 \pm 0.03$ at 15 and 22 days of age, respectively, and was significantly higher $(P<0.001$ at both ages) than the adult value of $1.08 \pm 0.02$. However, after 22 days of age the synchronization factor did not differ from that in adult animals. These data indicate that spermatogenesis was partially synchronized in Djungarian hamsters up to 22 days of age. In Wistar rats from 22 days of age onwards, all tubular cross-sections could be classified. No consistent enrichment of epithelial stages was found at any age examined. Furthermore, at any age tested the synchronization factor did not differ from adult values, confirming the lack of synchronization in the immature Wistar rat. The partial synchronization in immature Djungarian hamsters probably originates from the rather synchronous start of gonocyte proliferation. The lack of synchronization in immature rats is probably a consequence of the slower start of gonocyte proliferation in this species.
\end{abstract}

\section{Introduction}

The stages of the cycle of the seminiferous epithelium in tubular cross-sections of adult animals show a random distribution. The frequency of the spermatogenic stages is therefore regarded as an adequate measure of their relative duration (Leblond and Clermont, 1952a). The duration of the stages is not affected by alterations in gonadotrophin concentrations caused by hypophysectomy, hypophysectomy and concomitant treatment with testosterone propionate or chorionic gonadotrophin (Clermont and Harvey, 1965), or hemicastration (Noller et al., 1977). Depletion of specific spermatogenic cell types by exposure to $43^{\circ} \mathrm{C}$ for $15 \mathrm{~min}$ (Chowdhury and

*Correspondence.

Received 11 October 1993
Steinberger, 1964), or by treatment with alkylating agents (De Rooij and Kramer, 1970) does not affect the duration of the remaining stages. In the immature mouse the frequencies of the stages were shown to be altered by Nebel et al. (1961), whereas Kluin et al. (1982) found that they were similar to those in adult mice.

When vitamin $A$ is administered to vitamin-A-deficient rats, a labelling index of type A spermatogonia of about $50 \%$ is found after 24-30 h (Van Pelt and De Rooij, 1990), and subsequently a highly synchronous development of spermatogenesis takes place (Morales and Griswold, 1987; Van Beek and Meistrich, 1990; Van Pelt and De Rooij, 1990). In immature Djungarian hamsters spermatogenesis starts rather synchronously, with a labelling index of gonocytes of nearly $50 \%$ (Van Haaster et al., 1993). We investigated whether this high rate of gonocyte proliferation also results in a synchronous Downloaded from Bioscientifica.com at 04/26/2023 11:54:28AM 
development of spermatogenesis. In addition, since testicular cells of immature rats are frequently used for studies in vitro, we investigated whether synchronous development of spermatogenesis occurs in immature rats.

\section{Materials and Methods}

\section{Animals}

Djungarian hamsters (Phodopus sungorus sungorus) were born in our breeding colony, which was generously supplied by P. Niklowitz (Max Planck Clinical Research Unit for Reproductive Medicine, Münster). The colony was checked for litters once a day. Djungarian hamsters were killed, by decapitation or chloroform inhalation, on consecutive days from 4 to 9 days of age and at 15,22, 29, 43 and 64 days of age. The 4-9-day-old groups each consisted of six or seven animals; the 15-64-dayold groups consisted of five or seven animals. At all ages the animals were derived from at least two different litters.

Wistar rats at known stages of pregnancy were obtained from Harlan CPB (Zeist) or the Central Animal Facilities of the University of Utrecht (Utrecht). The rats were checked for litters twice daily. The rats were killed, by decapitation or chloroform inhalation, at consecutive days from 3 to 8 days of age and at 15,22, 28, 43, 64 and 85 days of age. Each age group consisted of four animals from at least two different litters.

For both species the day of birth was designated as day 1 , and pups were weaned at 3 weeks of age.

\section{Histology}

Two hours before they were killed the 4-9-day-old hamsters and the 3-8-day-old rats were injected s.c. with $150 \mathrm{mg}$ bromodeoxyuridine (BrdU) $\mathrm{kg}^{-1}$ body mass (Sigma Chemical $\mathrm{Co}$, St Louis, MO). The testes of these animals were fixed in Carnoy's fluid. The testes of the animals from 15 days of age onwards were fixed in Bouin's fluid. All testes were embedded in glycol methacrylate:butanediolmonoacrylate (BDH Laboratory Supplies, Poole; Klinipath BV, Zevenaar) at a ratio of $85: 15$. The BrdU label was visualized in $3 \mu \mathrm{m}$ sections of the testes fixed in Carnoy's fluid using monoclonal anti-BrdU and peroxidase-conjugated rabbit anti-mouse antibodies followed by a diaminobenzidine $-\mathrm{H}_{2} \mathrm{O}_{2}$ reaction, according to Harms et al. (1986) and Van de Kant et al. (1990). The sections were counterstained with Gill's haematoxylin (Polysciences Inc, Warrington, PA). In these sections the BrdU labelling index of gonocytes was scored. Sections, $5 \mu \mathrm{m}$ thick, of the testes fixed in Bouin's fluid were made at intervals of $250 \mu \mathrm{m}$, and stained with the periodic acid Schiff (PAS) technique and counterstained with Gill's haematoxylin. In these sections the frequencies of the spermatogenic cell types were scored.

\section{Morphological analysis}

Gonocytes were identified using the criteria described by Kluin and De Rooij (1981). The labelling index of gonocytes was determined by counting at least 500 gonocytes per animal.
The morphological criteria used to identify the spermatogenic cell types and the position of the mitoses of the differentiating spermatogonia in the spermatogenic cycle of Djungarian hamsters have been described by Van Haaster and De Rooij (1993a). $A_{3}$, intermediate (In) and B spermatogonia could be identified with certainty. However, $B_{1}$ and $B_{2}$ spermatogonia could not be distinguished from each other. As the transition between the steps of spermatocyte development is gradual, a clear identification of these cell types is sometimes difficult. The frequencies of the preleptotene, leptotene and zygotene spermatocytes were therefore pooled. However, the pachytene spermatocytes could be distinguished separately.

The differentiating spermatogonia $\left(A_{4}\right.$, In and $B$ spermatogonia could be distinguished) in Wistar rats were identified according to Hilscher et al. (1969). The position of mitoses of the differentiating spermatogonia during the seminiferous cycle was found to be as described by Hilscher et al. (1969). The transition between the zygotene and pachytene spermatocyte stages was found to occur between stages XIII and XIV, as described by Hess (1990). To distinguish between the 14 stages of spermatogenesis in Wistar rats the criteria of Leblond and Clermont (1952b) and those of Hess (1990), who described criteria for identifying the stages in plastic-embedded sections, were used.

\section{Frequencies of the stages}

The frequencies of the cellular associations present in immature animals were determined by examining at least 200 tubular cross-sections per animal. When a transition occurred from one cellular association to a subsequent one in a tubular cross-section, that association occupying more than $50 \%$ of the tubular cross-section was scored.

The data on the frequencies of the stages of the seminiferous cycle in adult Djungarian hamsters and Wistar rats were derived from our previous studies (Van Haaster and De Rooij, 1993a, b). In the study of the Djungarian hamster seminiferous epithelium, at least 200 tubular cross-sections per animal, in 17 animals (5-10 months of age), were staged. In the study dealing with spermatogenesis in rats at least 200 tubular cross-sections per animal, in 12 animals (6 months of age), were staged.

To compare the frequencies of the cellular associations in immature animals with those in adult animals, the frequencies of the stages in adult animals were pooled according to the position of mitoses of the differentiating spermatogonia and the spermatocyte steps during the seminiferous cycle.

\section{Synchronization factor}

For each animal a synchronization factor was calculated with the computer program SYNTEST, developed by Van Beek and Meistrich (1990). This program first calculates the stage with the lowest relative occurrence; this point is identified as the $0 / 100$ percentile point. Starting with this point, the 15.87, 50 and 84.13 percentile points are calculated. In normally distributed data these points would indicate the mean \pm SD. The window width is defined as the part of the cycle (expressed as a percentage) containing $68.26 \%$ of the staged 
Table 1. The frequencies of the stages of the seminiferous cycle in immature and adult Djungarian hamsters

\begin{tabular}{|c|c|c|c|c|c|c|}
\hline Stage & Day $15(7)^{a}$ & Day $22(5)$ & Day $29(7)$ & Day 43 (7) & Day $64(5)$ & Adult (17) \\
\hline I & $12.9 \pm 1.1^{\mathrm{b}}$ & $20.2 \pm 1.5^{\mathrm{b} * *}$ & $8.7 \pm 0.7$ & $8.0 \pm 0.9$ & $9.0 \pm 1.2$ & $7.7 \pm 0.6$ \\
\hline II & {$[12.7 \pm 0.7]$} & {$[12.7 \pm 0.7]$} & $8.0 \pm 0.9^{*}$ & $5.2 \pm 0.7$ & $5.0 \pm 0.6$ & $5.0 \pm 0.4$ \\
\hline III & $9.2 \pm 1.8 c^{c}$ & $12.6 \pm 1.4^{c}$ & $6.5 \pm 0.4^{*}$ & $4.4 \pm 0.6$ & $6.9 \pm 0.4^{*}$ & $4.2 \pm 0.4$ \\
\hline IV & {$[12.0 \pm 0.7]$} & {$[12.0 \pm 0.7]$} & $8.1 \pm 0.8$ & $7.1 \pm 0.9$ & $6.3 \pm 0.8$ & $7.9 \pm 0.4$ \\
\hline V & & & & $4.7 \pm 0.8$ & $5.6 \pm 0.3$ & $7.4 \pm 0.6$ \\
\hline VI & $\begin{array}{l}15.4 \pm 1.4^{\mathrm{d} * *} \\
{[34.3 \pm 1.0]}\end{array}$ & $\begin{array}{l}12.9 \pm 1.3 \mathrm{~d}^{\mathrm{d} * *} \\
{[34.3 \pm 1.0]}\end{array}$ & $\begin{array}{l}28.5 \pm 1.4^{\mathrm{d}} \\
{[34.3 \pm 1.0]}\end{array}$ & $13.3 \pm 1.0$ & $16.3 \pm 2.2$ & $15.3 \pm 0.8$ \\
\hline VII & & & & $20.0 \pm 1.4$ & $22.9 \pm 1.3$ & $23.3 \pm 1.2$ \\
\hline VIII & & & & $6.0 \pm 0.7$ & $5.1 \pm 0.7$ & $6.7 \pm 0.5$ \\
\hline IX & $\begin{array}{l}62.5 \pm 1.6^{e * *} \\
{[41.0 \pm 1.3]}\end{array}$ & $\begin{array}{l}46.0 \pm 1.4^{e * *} \\
{[34.1 \pm 1.1]}\end{array}$ & $\begin{array}{r}33.6 \pm 2.0^{\circ} \\
{[34.1 \pm 1.1]}\end{array}$ & $7.8 \pm 0.9^{*}$ & $5.6 \pm 0.3$ & $4.6 \pm 0.4$ \\
\hline$x$ & & & & $7.6 \pm 0.4^{* *}$ & $6.7 \pm 0.4$ & $4.5 \pm 0.4$ \\
\hline XI & & & & $9.0 \pm 1.8$ & $5.0 \pm 0.6$ & $6.7 \pm 0.6$ \\
\hline XII & & $8.2 \pm 0.8^{f}$ & $6.7 \pm 1.0^{f}$ & $6.3 \pm 0.4$ & $5.6 \pm 0.3$ & $6.8 \pm 0.5$ \\
\hline
\end{tabular}

Data are expressed as means \pm SEM. The frequencies of the corresponding pooled stages in adult animals are given in brackets. The frequencies that are printed in bold are significantly greater than those of adult animals.

${ }^{\text {a }}$ The number of animals tested is given in parentheses.

When necessary, the stages were pooled, based on the presence of ${ }^{b} A_{3}$ spermatogonia, intermediate (In) spermatogonia, ${ }^{d} B_{i}$ and $B_{2}$ spermatogonia, or epreleptotene-leptotene-zygotene spermatocytes. 'The stage at which meiotic divisions occur is distinguished as a separate group at the ages tested.

$* P<0.01$ and ${ }^{* *} P<0.001$ compared with adult values.

tubular cross-sections, distributed equally on both sides of the 50 percentile point. The synchronization factor is the window width of control animals divided by the window width of the synchronized animals (Van Beek and Meistrich, 1990). Control data for the SYNTEST program consist of the total number of tubules found in each stage in the control animals. When spermatogenesis is synchronized in an experimental animal, the synchronization factor is greater than 1 .

For each immature animal, a synchronization factor relative to the whole group of adult animals was calculated. To compare the immature animals with the adult animals, we also calculated a synchronization factor for each adult animal relative to the whole group of adult animals.

\section{Statistical analysis}

To obtain a normal distribution of the data, the frequencies of the cellular associations were first divided by 100 to obtain a fraction, which was then transformed to an arcsine. Subsequently, data were analysed using Student's $t$ test modified according to Bonferroni. Differences were considered significant when $P<0.01$. The synchronization factors were analysed with Bonferroni's $t$ test under the assumption of normality. Data are expressed as the mean \pm SEM.

\section{Results}

\section{Frequencies of the stages in immature animals}

In immature Djungarian hamsters at 15 days of age, the seminiferous tubules contained stages ranging from $A_{3}$ spermatogonia to pachytene spermatocytes associated with preleptotene spermatocytes. The cellular associations present could be divided into four groups, based on the presence of $A_{3}$, In or $B\left(B_{1}\right.$ and $\left.B_{2}\right)$ spermatogonia, or preleptotene-leptotenezygotene spermatocytes. When the frequencies of these cellular associations were compared with the frequencies of the corresponding pooled stages in adult animals, the group containing spermatocytes (i.e. from the middle of stage VII to stage XII) was found to be enriched by $52 \%$ above adult values $(P<0.001)$. Concomitantly, the occurrence of the B spermatogonia (i.e. from stage $\mathrm{V}$ to the middle of stage VII) was reduced by $55 \%$ compared with adult values $(P<0.001)$ (Table 1).

At 22 days of age in the Djungarian hamster the tubular cross-sections contained at least pachytene spermatocytes associated with $\mathrm{A}_{3}$ spermatogonia up to round spermatids in stage VI. The cellular associations could be divided into five groups, based on the presence of pachytene spermatocytes 
Table 2. The frequencies of the stages of the seminiferous cycle in immature and adult Wistar rats

\begin{tabular}{|c|c|c|c|c|c|c|}
\hline Stage & Day $22(4)^{\mathrm{a}}$ & Day $28(4)$ & Day $43(4)$ & Day $64(4)$ & Day $85(4)$ & Adult (12) \\
\hline I I & $\begin{array}{r}14.7 \pm 2.0^{\mathrm{b}} \\
{[17.9 \pm 1.0]}\end{array}$ & $\begin{array}{c}19.4 \pm 2.3^{\mathrm{b}} \\
{[17.9 \pm 1.0]}\end{array}$ & $14.9 \pm 1.3$ & $14.2 \pm 1.8$ & $11.5 \pm 1.3$ & $15.6 \pm 0.9$ \\
\hline II & & & $4.6 \pm 0.4$ & $5.6 \pm 1.1$ & $5.3 \pm 1.1$ & $4.2 \pm 0.7$ \\
\hline III & $\begin{array}{r}9.5 \pm 1.2^{c} \\
{[12.9 \pm 1.0]}\end{array}$ & $\begin{array}{r}10.4 \pm 1.5^{c} \\
{[12.9 \pm 1.0]}\end{array}$ & $2.8 \pm 0.7$ & $2.7 \pm 0.8$ & $4.6 \pm 1.0$ & $4.1 \pm 0.4$ \\
\hline IV & & & $3.0 \pm 0.4$ & $3.2 \pm 1.0$ & $4.0 \pm 0.4$ & $4.1 \pm 0.5$ \\
\hline V & $\begin{array}{c}11.7 \pm 1.4^{\mathrm{d}} \\
{[9.8 \pm 0.7]}\end{array}$ & $\begin{array}{r}8.9 \pm 1.9^{\mathrm{d}} \\
{[9.8 \pm 0.7]}\end{array}$ & $6.3 \pm 1.3^{*}$ & $5.7 \pm 1.0$ & $4.4 \pm 1.0$ & $3.5 \pm 0.3$ \\
\hline VI & & & $7.3 \pm 0.5$ & $8.8 \pm 0.7$ & $9.0 \pm 0.3$ & $6.3 \pm 0.8$ \\
\hline VII & & & $20.3 \pm 1.9$ & $24.2 \pm 1.5$ & $21.2 \pm 1.9$ & $23.8 \pm 1.0$ \\
\hline VIII & & & $5.9 \pm 0.4$ & $8.3 \pm 1.6$ & $6.3 \pm 1.2$ & $5.0 \pm 0.6$ \\
\hline IX & & & $5.0 \pm 1.0$ & $3.6 \pm 1.1$ & $4.6 \pm 0.6$ & $5.8 \pm 0.5$ \\
\hline$x$ & $\begin{array}{r}64.1 \pm 2.0^{\mathrm{e}} \\
{[59.4 \pm 1.6]}\end{array}$ & $\begin{array}{c}61.3 \pm 4.1^{e} \\
{[59.4 \pm 1.6]}\end{array}$ & $3.0 \pm 0.3$ & $2.0 \pm 0.5$ & $3.3 \pm 0.6$ & $3.3 \pm 0.2$ \\
\hline XI & & & $3.5 \pm 0.4$ & $3.6 \pm 0.5$ & $4.1 \pm 0.3$ & $3.1 \pm 0.3$ \\
\hline XII & & & $3.6 \pm 0.5$ & $3.8 \pm 0.5$ & $5.7 \pm 1.3$ & $5.9 \pm 0.8$ \\
\hline XIII & & & $9.6 \pm 1.1$ & $9.5 \pm 1.8$ & $11.5 \pm 1.7$ & $10.4 \pm 0.8$ \\
\hline XIV I & & & $10.2 \pm 1.6^{* *}$ & $4.8 \pm 0.4$ & $4.6 \pm 0.7$ & $5.0 \pm 0.4$ \\
\hline
\end{tabular}

Data are expressed as means \pm SEM. The frequencies of the corresponding pooled stages in adult animals are given in brackets. The frequencies that are printed in bold are significantly increased.

${ }^{a}$ The number of animals tested is given in parentheses.

When necessary, the stages were pooled, based on the presence of pachytene spermatocytes associated with ${ }^{b} \mathrm{~A}$ spermatogonia, with intermediate (In) spermatogonia, or with ${ }^{\mathrm{d}} \mathrm{B}$ spermatogonia, or ${ }^{\mathrm{e}}$ preleptotene-leptotene-zygotene spermatocytes.

${ }^{*} P<0.01$ and ${ }^{* *} P<0.001$ compared with adult values.

associated with $A_{3}$ spermatogonia, with In spermatogonia, with B spermatogonia, or with preleptotene-leptotenezygotene spermatocytes, or the meiotic divisions. An enrichment was found of cellular associations containing pachytene spermatocytes associated with $A_{3}$ spermatogonia, and of those containing pachytene spermatocytes with preleptoteneleptotene-zygotene spermatocytes (i.e. from the middle of stage VII to stage XI; $P<0.001$ for both groups). The crude counts showed that the enrichment observed in the pachytene spermatocytes with $A_{3}$ spermatogonia was mainly due to an increased occurrence of tubular cross-sections containing round spermatids in stages I and II. The frequency of the meiotic divisions (stage XII) was also increased at this age, but this increase was not statistically significant. A reduced frequency was found for pachytene spermatocytes associated with $B$ spermatogonia $(P<0.001)$.

At 29 days the cellular associations found ranged from pachytene spermatocytes with B spermatogonia up to elongated spermatids in stage VII. These spermatogenic cell types were classified into seven groups: pachytene spermatocytes associated with B spermatogonia and with preleptoteneleptotene-zygotene spermatocytes, the meiotic divisions and stages I-IV. An enrichment was found in stages II and III compared with adult values, mainly due to an increased frequency of tubular cross-sections in these stages containing elongated spermatids $(P<0.01$ for both stages). From 43 days of age onwards, all tubules contained round or elongated spermatids and were classified into the 12 stages of spermatogenesis. At 43 days of age stages IX $(P<0.01)$ and $X$ $(P<0.001)$ were enriched. At 64 days only stage III was found to be enriched $(P<0.01)$.

At 15 days of age in the Wistar rat, some tubules could still be found that contained only unidentifiable type $A$ spermatogonia, which could either be undifferentiated or early differentiating type $A\left(A_{1}-A_{3}\right)$ spermatogonia. Hence, no reliable frequency distribution could be made at 15 days of age. However, at 22 days of age the cell types present ranged from preleptotene spermatocytes up to round spermatids in stage III. They were assigned to the following groups: preleptotene-leptotene-zygotene spermatocytes, pachytene spermatocytes associated with $A$, with In, or with $B$ spermatogonia. No differences were found when the frequencies were compared with those in adult animals (Table 2). At 28 days, spermatogenesis had advanced from 


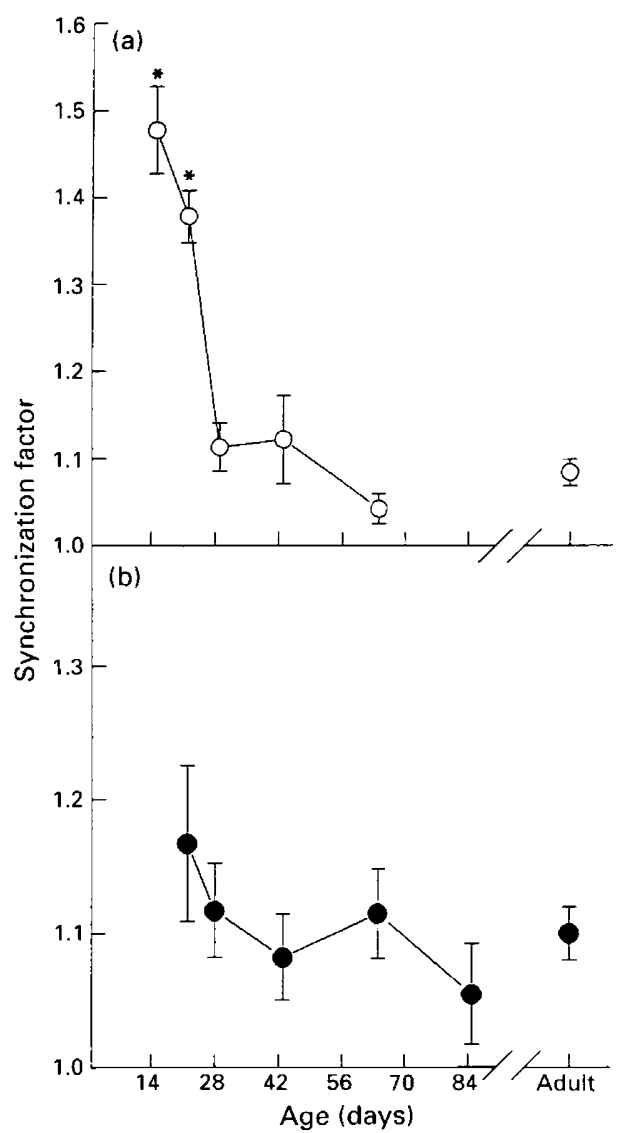

Fig. 1. The synchronization factor of the seminiferous epithelium of (a) Djungarian hamsters $(O)$ and (b) Wistar rats (O) during development. Vertical bars represent SEM. ${ }^{*} P<0.001$ compared with adult animals.

at least pachytene spermatocytes with A spermatogonia up to round spermatids in stage VII. No significant differences were found when the frequencies were compared with those in adult animals. At 43 days of age, when spermatogenesis could be divided into 14 stages, stages $\mathrm{V}$ $(P<0.01)$ and XIV $(P<0.001)$ were found to be enriched. However, at 64 and 85 days, no significant differences were observed.

\section{Synchronization factor}

Synchronization factors were calculated for each of the immature and adult animals using the computer program SYNTEST. In adult hamsters and rats the average synchronization factor was greater than one, probably owing to variations in the estimated frequencies of stages between the individual adult animals. In Djungarian hamsters a synchronization factor that was significantly higher than in adult animals was found at 15 and 22 days of age $(P<0.001$ at both ages). However, from 29 days onwards the synchronization factors were not different from those in adult animals. In immature Wistar rats the synchronization factors found did not differ from those in adult animals at any of the ages examined (Fig. 1).

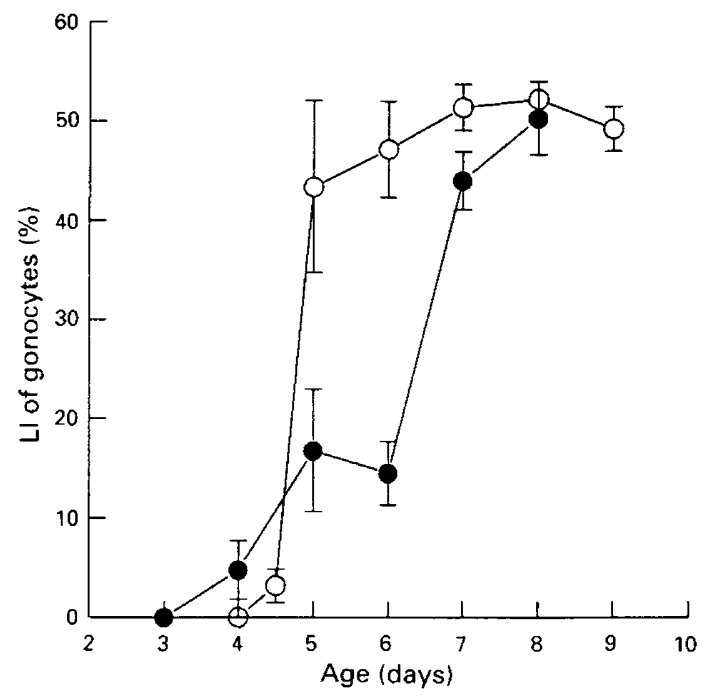

Fig. 2. The bromodeoxyuridine labelling index (LI) of gonocytes in the neonatal Djungarian hamster $(O)$ and Wistar rat $(0)$. Vertical bars represent SEMS.

\section{Proliferation of gonocytes}

To explain the differences between Djungarian hamsters and the Wistar rats, we determined the labelling indices of gonocytes in both species using BrdU. It was found that in the Djungarian hamster, many gonocytes enter the $\mathrm{S}$ phase of the cell cycle, with a labelling index of nearly $50 \%$ on day 5 , as described by Van Haaster et al. (1993). In Wistar rats, the proliferative activity of gonocytes was relatively low from day 4 to day 6 . Labelling indices of nearly $50 \%$ were found only at 7 and 8 days of age, when most of the gonocytes had already divided to form type A spermatogonia (Fig. 2).

\section{Discussion}

In the immature Djungarian hamsters, a clear enrichment in the frequency of specific spermatogenic cell types and a reduction in the frequency of others was observed at 15 and 22 days of age. In addition, a significantly higher synchronization factor was found at these ages, indicative of a synchronous initial development of spermatogenesis. The progression of the synchronization from 15 to 22 days of age was somewhat faster than could be expected from the duration of the spermatogenic cycle of 7.9 days in adult Djungarian hamsters (Van Haaster and De Rooij, 1993a). However, this could be due to an accelerated rate of spermatogenic progression, which has been found to occur in Djungarian hamsters up to about 15 days of age (Van Haaster and De Rooij, 1993b). From 29 days of age onwards only one or a few stages were found to occur more often than in the adult. Possibly, these were remnants of the earlier synchronization. However, at these ages the synchronization factor did not differ from that in adults.

The fast disappearance of the synchronization, indicated by the fast decrease in the synchronization factor, might be caused by variations in the duration of the cycle and the stages between and within animals. However, if this was the only 
cause for the lack of synchronization, the synchronization factor would be expected to decrease at a rate comparable to that after vitamin A replacement. This is not the case, as even after 128 days a synchronization factor of about 1.7 is found (Van Beek and Meistrich, 1990). The increase in tubular length in immature animals, which is caused by Sertoli cell proliferation and a gradual increase in the number of germinal cells per Sertoli cell, may also help to decrease the level of synchronization.

After vitamin A replacement in vitamin-A-deficient rats, the synchronization originates from a massive start of proliferation of $A_{1}$ spermatogonia (Van Pelt and De Rooij, 1990). In view of this, the partial synchronization of spermatogenesis in immature Djungarian hamsters could be caused by the highly synchronous start of gonocyte proliferation at postnatal day 5 , when a labelling index of almost $50 \%$ is found. In the immature Wistar rat no significant synchronization of spermatogenesis was observed. However, the pattern of gonocyte proliferation in the immature rat differed from that in the Djungarian hamster: the labelling index was relatively low on days 4-6 and only approached $50 \%$ at days 7 and 8 , when most of the gonocytes have divided into A spermatogonia. Taken together, these results indicate that there is a relationship between the degree of synchrony of gonocyte proliferation at the start of spermatogenesis and the degree of synchrony of the spermatogenic process following this start.

For studies in vitro testicular cells are frequently isolated from testes of 3-week-old rats. The results reported here show that in Wistar rats the distribution of the cellular associations present at that age does not differ significantly from that in adult rats. However, in Djungarian hamsters synchronization was clearly present in animals 15 and 22 days old, resulting in a higher or lower occurrence of some of the epithelial stages. These results imply that when, for example, cyclic functions of Sertoli cells are investigated, data obtained in prepubertal Djungarian hamsters should be interpreted with care.

In adult Djungarian hamsters and rats, the average synchronization factors found were greater than one. Since the synchronization factor for each of the adult animals was calculated relative to the whole group of adult animals, this can be explained by variations in the frequency of the stages between the animals. Van Beek and Meistrich (1991) considered spermatogenesis to be synchronized when the synchronization factor was higher than 1.5. However, by calculating the synchronization factor for control animals the degree of synchrony in the experimental animals can be statistically tested. With this procedure the reliability of the results can therefore be improved.

In conclusion, our data show that in species or strains of species in which gonocytes at the start of spermatogenesis enter the $S$ phase at a high rate, spermatogenesis can be synchronous to some degree at later ages. When studying aspects of spermatogenesis that may vary at different epithelial stages, a possible synchronization in immature animals should be taken into account. In addition, when determining frequencies of epithelial stages in a species, it is recommended that animals are used in which spermatogenesis is not only complete, but that have also passed through several additional cycles, to avoid problems caused by a possible synchronization of spermatogenesis.
The authors wish to thank H. L. Roepers-Gajadien for skillful technical assistance, and M. E. A. B. van Beek for providing the SYNTEST program.

\section{References}

Chowdhury AK and Steinberger E (1964) A quantitative study of the effect of heat on germinal epithelium of rat testes American Journal of Anatomy 115 509-524

Clermont $Y$ and Harvey SC (1965) Duration of the cycle of the seminiferous epithelium of normal, hypophysectomized and hypophysectomized hormone-treated albino rats Endocrinology 76 80-89

De Rooij DG and Kramer MF (1970) The effect of three alkylating agents on the seminiferous epithelium of rodents Virchows Archiv Abteilung B Zellpathologie $4267-275$

Harms G, Van Goor H, Koudstraal J, De Ley L and Hardonk MJ (1986) Immunohistochemical demonstration of DNA-incorporated 5bromodeoxyuridine in frozen and plastic embedded sections Histochemistry 85 139-143

Hess RA (1990) Quantitative and qualitative characteristics of the stages and transitions in the cycle of the rat seminiferous epithelium: light microscopic observations of perfusion-fixed and plastic-embedded testes Biology of Reproduction 43 525-542

Hilscher B, Hilscher W and Maurer W (1969) Autoradiographische Untersuchungen über den Modus der Proliferation und Regeneration des Samenepithels der Wistarratte Zeitschrift für Zellforschung 94 593-604

Kluin PM and De Rooij DG (1981) A comparison between the morphology and cell kinetics of gonocytes and adult type undifferentiated spermatogonia in the mouse International Journal of Andrology 4 475-493

Kluin PM, Kramer MF and De Rooij DG (1982) Spermatogenesis in the immature mouse proceeds faster than in the adult International Journal of Andrology 5 282-294

Leblond CP and Clermont Y (1952a) Spermiogenesis of rat, mouse, hamster and guinea pig as revealed by the 'periodic acid-fuchsin sulfurous acid' technique American Journal of Anatomy 90 167-215

Leblond CP and Clermont Y (1952b) Definition of the stages of the cycle of the seminiferous epithelium in the rat Annals of the New York Academy of Sciences 55 548-573

Morales C and Griswold MD (1987) Retinol-induced stage synchronization in seminiferous tubules of the rat Endocrinology $121432-434$

Nebel BR, Amarose AP and Hackett EM (1961) Calendar of gametogenic development in the prepubertal male mouse Science 134 832-833

Noller DW, Howards SS and Flickinger CJ (1977) Duration of the seminiferous epithelial cycle in the mature guinea pig: influence of unilateral orchiectomy Fertility and Sterility $28998-1002$

Van Beek MEAB and Meistrich ML (1990) A method for quantifying synchrony in testes of rats treated with vitamin A deprivation and readministration Biology of Reproduction 42 424-431

Van Beek MEAB and Meistrich ML (1991) Stage-synchronized seminiferous epithelium in rats after manipulation of retinol levels Biology of Reproduction 45 235-244

Van de Kant HJG, Van Pelt AMM, Vergouwen RPFA and De Rooij DG (1990) A rapid immunogold-silver staining for detection of bromodeoxyuridine in large numbers of plastic sections, using microwave irradiation Histochemical Journal 22 321-326

Van Haaster LH and De Rooij DG (1993a) The cycle of the seminiferous epithelium in the Djungarian hamster (Phodopus sungorus sungorus) Biology of Reproduction 48 515-521

Van Haaster LH and De Rooij DG (1993b) Spermatogenesis is accelerated in the immature Djungarian and Chinese hamster and rat Biology of Reproduction 49 1229-1235

Van Haaster LH, Van Eerdenburg FJCM and De Rooij DG (1993) Effect of prenatal and postnatal photoperiod on spermatogenic development in the Djungarian hamster (Phodopus sungorus sungorus) Journal of Reproduction and Fertility $97223-232$

Van Pelt AMM and De Rooij DG (1990) The origin of the synchronization of the seminiferous epithelium in vitamin A-deficient rats after vitamin A replacement Biology of Reproduction 42 677-682 